\title{
Perpetual growth, the labor share, and robots
}

Citation for published version (APA):

Nomaler, Ö., \& Verspagen, B. (2020). Perpetual growth, the labor share, and robots. Economics of Innovation and New Technology, 29(5), 540-558. https://doi.org/10.1080/10438599.2019.1643557

Document status and date:

Published: 01/01/2020

DOI:

10.1080/10438599.2019.1643557

Document Version:

Publisher's PDF, also known as Version of record

Document license:

Taverne

\section{Please check the document version of this publication:}

- A submitted manuscript is the version of the article upon submission and before peer-review. There can be important differences between the submitted version and the official published version of record.

People interested in the research are advised to contact the author for the final version of the publication, or visit the DOI to the publisher's website.

- The final author version and the galley proof are versions of the publication after peer review.

- The final published version features the final layout of the paper including the volume, issue and page numbers.

Link to publication

\footnotetext{
General rights rights.

- You may freely distribute the URL identifying the publication in the public portal. please follow below link for the End User Agreement:

www.umlib.nl/taverne-license

Take down policy

If you believe that this document breaches copyright please contact us at:

repository@maastrichtuniversity.nl

providing details and we will investigate your claim.
}

Copyright and moral rights for the publications made accessible in the public portal are retained by the authors and/or other copyright owners and it is a condition of accessing publications that users recognise and abide by the legal requirements associated with these

- Users may download and print one copy of any publication from the public portal for the purpose of private study or research.

- You may not further distribute the material or use it for any profit-making activity or commercial gain

If the publication is distributed under the terms of Article $25 \mathrm{fa}$ of the Dutch Copyright Act, indicated by the "Taverne" license above, 


\title{
Perpetual growth, the labor share, and robots
}

\author{
Önder Nomaler and Bart Verspagen (c)
}

UNU-MERIT, Maastricht, The Netherlands

\begin{abstract}
The recent literature on the economic effects of machine learning, robotization and artificial intelligence suggests that there may be an upcoming wave of substitution of human labor by machines. We argue that these new technologies may lead to so-called perpetual growth, i.e. growth of per capita income with a non-progressing state of technology. We specify an exact parameter threshold beyond which perpetual growth emerges, and argue that ongoing technological change may bring the threshold in reach. We also show that in a state of perpetual growth, factor-eliminating technological progress reduces the role of labor in the production process and that this leads to a rising wage rate but ever-declining share of wage income. We present simulation experiments on several policy options to combat this inequality, including a universal basic income as well as an option in which workers become owners of 'robots'.
\end{abstract}

\section{KEYWORDS}

Perpetual economic growth; economic effects of robots; labor share in income; income distribution

\section{JEL CLASSIFICATION} O41; 033; E25; P17

\section{Introduction}

Discussions about new technologies replacing labor are as old as the economics academic discipline. Frey and Osborne $(2017,256)$ quote Queen Elizabeth I speaking out against an innovative knitting machine, in support of her 'poor subjects'. Freeman and Soete (1994) quote David Ricardo entertaining the view that 'the employment of machinery is frequently detrimental to [the] interests' of the working class. In this sense, the recent debate on the expected impact of advanced computer technologies replacing labor (e.g. Frey and Osborne) is not new.

However, if an individual innovation replaces labor, this does not necessarily mean that unemployment will arise in the aggregate economy. The total employment effects of technological innovation will consist of both direct effects (e.g. introduction of labor-saving machines) and indirect effects (e.g. increased demand for labor due to increased product demand as a result of a fall in prices due to the innovation, or as a result of product innovation). Economic theory and models exist to analyze the interplay (and net effect) of these direct and indirect effects (Vivarelli 1995). For the net employment effect of innovation to settle may take long periods of adjustment (Freeman and Soete 1994), but in recent contributions that take a broader economy-wide perspective instead of focusing on automation only, seems to lead to more optimism about long-run employment trends (Autor 2015; Bessen 2016; Autor and Salomons 2018).

On the other hand, the impact of innovation and new technology on the labor market is not limited to quantity effects (employment), but also affects prices (wages) (e.g. Katsoulacos 1986). In this respect, the observed secular decline in the share of wages in GDP is interesting. As noted by the IMF $(2017,121)$ : '[i]n advanced economies, labor income shares began trending down in the 1980s, reaching their lowest level of the past half century just prior to the global financial crisis of 
2008-09, and have not recovered materially since'. This trend may be related to technological change in different ways.

For example, Autor et al. (2017) argue that new technologies are often associated to network externalities and low marginal costs, leading to superstar firms dominating the economy and paying a lower share of value added to wages. Technological change may also change the relative prices of capital and labor, making investment goods relatively cheaper. This provides an incentive for firms to replace labor by capital (Karabarbounis and Neiman 2014; Autor and Salomons 2018). The extent to which this happens may differ between routine and non-routine tasks that workers of different skill levels perform (Autor and Dorn 2013; Acemoglu and Restrepo 2017), which is an idea that is also present in the large literature on so-called skills-biased technological change (e.g. Acemoglu 1998, 2002; Berman, Bound, and Machin 1998; Murphy, Riddell, and Romer 1998; Card and DiNardo 2002; Acemoglu and Autor 2011). This literature addresses, among other things, the apparent paradox that, we observe both a rise of a skills-premium in wages (and associated inequality between skilled and unskilled workers), and a rising relative supply of highly skilled workers. The paradox is solved by looking at technological change, especially information and communication technologies, as biased towards replacing routine tasks performed by low-skilled workers. Thus, wages of low skilled workers may be a major factor behind the declining total wage share in income.

Our interest in this paper is to relate the debate on machine learning and related technologies to the observation of a secularly declining labor income share as observed by, among others, the IMF. In other words, we want to shift the interest in machine learning, robots and artificial intelligence away from the pure employment effects, ${ }^{1}$ towards a deeper understanding of inequality. In particular, we are interested in exploring the view that these new technologies will be different from previous waves of technological change, because their potential to substitute capital for labor is very high, and that this may lead to inequality levels that are unprecedented in economic history.

One the other hand, it is also clear that these technologies have a high potential to create (extra) economic growth. This dual growth and inequality enhancing nature of robots and related technologies is the prime focus of our paper. Our contention is that once robot technology ${ }^{2}$ reaches a threshold level of maturity, growth will become self-propelling and independent of technological advances ('perpetual growth'), while at the same time the distribution of income between workers and the owners of capital will shift dramatically in favor of the latter. In analyzing this potential transition towards perpetual growth, we will ignore the employment effects of the robot technologies.

Perpetual growth takes place by investment in capital only (i.e. no further investment in technology, such as Research and Development, $R \& D$, is necessary for growth). This clearly puts our analysis in the realm of economic growth. Technological change has long been considered a main determinant of economic growth (e.g. Nelson and Winter 1982; Lucas 1988; Romer 1990; Silverberg and Verspagen 1994). The foundations of the model that we present are similar to Acemoglu and Restrepo (2017), who present a growth model in which technology can either take the form of automating (replacing) human labor, or create new 'tasks' that contribute to production and can only be performed by humans. Although their model potentially yields a growth path in which all human labor is replaced by capital, the emphasis of their analysis is on a path in which the two types of technological change balance each other out. In their model,

there are powerful self-correcting market forces pushing the economy towards balanced growth (...) for example the arrival of a series of new automation technologies, will set in motion self-correcting forces (...) there will be an adjustment process restoring the level of employment and the labor share back to their initial values. (p. 28)

Our interest, on the other hand, is in the situation where the labor-replacing technologies create perpetual growth as described above. We do not model the emergence of perpetual growth as an endogenous process, but instead formulate a general model that encompasses both perpetual growth (growth is driven only by investment) and the more traditional state in which growth is impossible without productivity-enhancing activities such as R\&D. We will then analyze which parameter values differentiate between these two states, i.e. we formulate a threshold parameter 
condition under which perpetual growth becomes feasible, and provide an economic interpretation of this threshold.

The remainder of this paper is organized as follows. In the next section, we will briefly discuss our ideas on the economic impact of robot-technology and relate them to the existing literature. We will also touch upon the way in which this form of technological change can be analyzed in economic models. Section 3 will present the production function that will be the basis of our model. It will describe how the micro foundations of the production function may be related to the findings in the existing literature. It also introduces the parameters that will make up the threshold condition for perpetual growth, and thereby provides the foundation of the economic interpretation of this threshold.

Section 4 will show how the production function can be embedded in a simple growth model. As we are interested in the effects of technology on inequality and not on employment, the model will assume (for simplicity) an infinitely inelastic supply of labor. In Section 5, we analyze the model to investigate under what conditions (perpetual) growth will emerge, and how the growth rate can be quantified. Section 6 will look at the dynamics of the labor income share and the wage rate, both along the steady state of perpetual growth, and in the transient towards the steady state. Section 7 explores some options for combatting inequality that may result from perpetual growth, by means of a social protection policy. The analysis here is by means of numerical simulations. Section 8 summarizes the argument, draws some conclusions, and outlines some avenues for further research.

\section{Capital, labor, and robots}

The recent empirical debate on so-called automation risk (Arntz, Gregory, and Zierahn 2016; Frey and Osborne 2017; Nedelkoska and Quintini 2018) follows Autor, Levy, and Murnane (2003) in applying a two-way categorization of labor tasks, i.e. routine vs. non-routine tasks and cognitive vs. manual tasks, and argues that the domain of non-routine (i.e. non-automatable) tasks is rapidly shrinking. In this context, 'automatable' or 'automation' means that human labor is substituted by capital goods, in particular machine learning (ML) and mobile robotics (MR). Frey and Osborne $(2017,258)$ view ML as a way to automate cognitive tasks previously performed by human labor, and MR as a way of automating manual work. This leads us to argue that while economic theory traditionally looks at factorenhancing technological progress, robots and related technologies may be better characterized as what Peretto and Seater (2013) call factor-eliminating technical change, with strong consequences especially for the distribution of income between capital and labor (e.g. IMF 2017, chapter 3).

We may consider a basic example to illustrate this distinction. A basic shovel, probably made of some kind of metal, greatly improved human productivity in the production task of moving earth (digging). The invention of mechanical diggers, first powered by steam and later by fossil fuels, again greatly improved productivity in this task. A human operating a mechanical digger can move much larger amounts of soil in a fixed amount of time than a single human using a shovel, who can in turn move larger amounts than a human using just bare hands. The shovel and the mechanical digger are pieces of capital that embody technology that complements human labor by making it more productive. Some workers may lose their jobs as shovel operators when mechanical diggers are introduced, or as bare hand diggers when shovels are introduced. Therefore these pieces of equipment may substitute for human labor, depending on total demand in the industry. Workers that are substituted in this way may, in the longer run, as a result of indirect effects such as an increased demand for digging services, be re-employed (after acquiring new skills) as operators of the new technology. In this case, they will tend to end up being better-off due to higher wages that reflect higher productivity.

Under the influence of machine learning, however, the mechanical digger could be made selfoperating, just as autonomous (self-driving) cars are now being developed. Such an autonomous digger would substitute entirely for human labor, and the task of moving earth could, under at 
least some circumstances, be carried out without any input of humans. This ultimate step in technological progress (robotization) is very different than those before, since it puts the worker out of a job without any perspective of being re-employed in the digging business. Even though this worker may find employment of some other type (e.g. building, designing or maintaining autonomous digging machines), as our analysis will show, there will be severe effects of this kind of innovation on the distribution of income between labor and capital, but also on economic growth.

This effect on the labor share in income and growth of technological progress that completely substitutes labor is the main focus of our analysis. We will not consider how this form of technological progress comes about endogenously, but instead assume that it will (soon) reach a state in which it can start to play a new role in the economy, i.e. what Pratt (2015) calls a 'Cambrian explosion for robotics'. In the next section, we introduce a production function in which a few parameters distinguish between a pre- and post-Cambrian explosion of robots. The analysis of growth model that incorporates this production function in Section 4 and beyond will first identify the parameter threshold that reflects this Cambrian explosion, and then analyse the consequences of it in terms of growth and the labor share of income.

Two main issues motivate our work. First, factor-eliminating technological change creates a strong potential for economic growth. In particular, it may change the game of technological progress completely. Factor-augmenting technological progress requires a constant investment in research and development or science (e.g. Romer 1990), or human capital (e.g. Lucas 1988). But after reaching a critical level of advancement in factor-eliminating technologies, investment in technology or knowledge will no longer be necessary to keep growth going. Instead, growth can be sustained merely by further investment in the ultimately-conceived capital vintage. In other words, the constant state of technological knowledge is enough to fuel growth by capital investment alone.

This kind of growth has been called perpetual growth (e.g. Prettner 2019). Although we (and Prettner) will associate it to what Frey and Osborne call machine learning, it is hardly a new idea. Solow $(1956,78)$ already coined the possibility when discussing the constant elasticity of substitution (CES) production function in the context of his growth model: under certain parameter conditions, ${ }^{\prime}$... the capital-labor ratio increases indefinitely and so does real output per head. The system is highly productive and saves-invests enough at full employment to expand very rapidly'.

The idea of perpetual growth is, however, just a footnote in the contribution of Solow (1956). His main contribution was to show that in the presence of a non-reproducible production factor (i.e. labor) that has somewhat limited substitutability with a reproducible production factor (capital), growth of per capita output would eventually halt, unless the productivity of the non-reproducible factor could be augmented in some way (by technological progress). The model that was presented by Solow depends heavily on a so-called Cobb-Douglas aggregate production function, which excludes the possibility of perpetual growth (Solow 1956, 76).

In terms of our digging example, giving a single worker more than one shovel does not lead to higher quantities of earth moved by that worker (i.e. the marginal returns to capital are decreasing). With a given demand for digging services, growth of the diggers' income is not possible by endowing them with more shovels. The introduction of mechanical diggers, on the other hand, would enable fewer workers to do the job, which means rising productivity and rising income for the workers that remain. But again, after all qualified operators are provided with one mechanical digger, there is no point in investing further in more mechanical diggers. It is this kind of technological progress (i.e. factor augmenting) that can be accommodated in Solow's Cobb-Douglas production function. On the other hand, as illustrated by the above Solow quotation, a CES production function opens up a wider range of growth opportunities.

Solow's CES corollary was not taken up by the endogenous growth literature that developed in the 1980s and 1990s. Instead, the focus was on formal conceptual frameworks (models) where sustainability of growth is strongly dependent on technological change that counteracts diminishing marginal returns to capital, for example by a succession of labor-augmenting inventions embodied in intermediate goods (Romer 1990), or investment in human capital (Lucas 1988). However, now 
that we are beginning to realize that cumulative technological progress has enormously increased the substitutability of labor (even its cognitive faculties) with certain types of capital, there is a need to develop a new formal conceptual framework to study growth (of the perpetual type).

Solow's corollary points to the CES-based aggregate production functions as a way forward on this path. Acemoglu and Restrepo $(2017,10)$ show that an aggregate CES production function of the type that we will be using (i.e. with labor and 'robot capital' as the two production factors) may be derived from a micro foundation in which human labor tasks can be automated, in the sense of Frey and Osborne. Our approach below will combine automation with factor-augmenting technological progress and hence will require distinguishing between two basic types of capital: one that embodies each form of technological change that we identified.

The second issue that motivates our approach is that under a state of perpetual growth, labor as a production factor will potentially receive an ever-declining share of total income, which leads to high inequality. We are interested here both in the question whether and how quickly this inequality arises, and in how it can be combatted. To investigate the latter issue, we will build into our model a number of experiments that mimic social protection policies, including a universal basic income.

What we will not investigate in the model that we present below are the employment consequences of factor-eliminating technological progress. In fact, we will assume that labor supply is infinitely inelastic and will therefore always be fully employed (this is also the standard assumption in Solow's growth model). We do not necessarily believe that this is a realistic assumption, but nevertheless make it because we feel that in the context of perpetual growth, the income distribution issue is much more salient than the employment issue. After all, perpetual growth ultimately makes employment superfluous, because factor-eliminating technological progress reduces the role of labor in the production process greatly.

The occurrence of perpetual growth in our model hinges on three major factors: the share of human work that can potentially be automated, the relative costs of labor-replacing capital vs. labor, and the elasticity of substitution between labor and labor-replacing capital. If labor-replacing capital ('robots') gets cheaper, if more labor tasks can be substituted by robots, and if human and robot labor can be substituted more easily, perpetual growth is more likely to occur.

Our approach is similar to Prettner's (2019) model of perpetual growth, although he assumes perfect substitutability between labor and robots. Our results show that this is an unnecessarily strict assumption, and that perpetual growth may already arise when substitution is far from perfect, i.e. at an earlier stage of development of machine learning technology. DeCanio (2016) employs a production function similar to ours, in an analysis aimed at identifying the impact of robotization on wages. The approach in Peretto and Seater's (2013) model is different and does not involve either costs or the elasticity of substitution.

\section{A production function for robotization}

We formalize the ideas from the previous section in the following production function:

$$
Q=\left(\alpha\left(b_{o} K_{o}\right)^{\mu}+(1-\alpha)\left[\beta\left(b_{s} K_{s}\right)^{\rho}+(1-\beta)\left(b_{L} L\right)^{\rho}\right]^{\mu / \rho}\right)^{1 / \mu}
$$

$Q$ is output, $L$ is labor input (employment), $K_{o}$ and $K_{s}$ are different kinds of capital that we will discuss in detail below, $\mu$ and $\rho$ are parameters related to substitutability in the production process, and $a, \beta$, $b_{o}, b_{s}$ and $b_{L}$ are other parameters to be discussed below. We consider a homogenous labor input, i.e. do not distinguish between different kinds of labor, such as high-skilled and low-skilled, or blue and white collar. The empirical work on the automation risk surveyed above suggests that labor of all kinds may be automated, although it may also be true that some kinds of labor have a higher risk than others. We deliberately abstract, however, from making such a distinction, to keep the analysis simple, and in order to bring out the results of the analysis in a sharp way. 
The reason for assuming two different kinds of capital goods lies in the variety of productive services that can jointly produce output $Q$. Some of these services can be produced by tasks carried out by human labor $L$ (in a combination of physical and cognitive activities). Examples of these kinds of services are bricklaying or composing music. Some of these kinds of 'human-like' activities can also be performed by machines (including software), but the key element of their definition is that all of them can in principle be performed by the human body and mind. The kind of capital that may replace these human-like activities will be referred to as $K_{s}$. It is what is often referred to as 'robots', but includes a broad set of technologies such as artificial intelligence or machine learning. The activities that are produced by either $L$ or $K_{s}$ are exactly the kinds of activities that Frey and Osborne argue may be automated in the (near) future.

The production factors $K_{s}$ and $L$ may use varying amounts of a different kind of capital, which is denoted by $K_{o}$. The key characteristic of this kind of capital is that it produces services that a human body or mind cannot deliver. As an example of capital type $K_{o}$, one may think of a blast furnace, an office building, or a lithography machine used to produce silicon chips. All of these types of capital perform services that a human body or brain cannot provide.

Capital goods are measured in monetary terms (dollars), and labor in time (such as person-hours). The productivity parameters $b_{o}, b_{s}$ and $b_{L}$ convert these units into output $Q$. The production function is nested. Labor $L$ and capital $K_{s}$ form a composite production factor in the 'inner part' of the function. This composite production factor follows a logic similar to Acemoglu and Restrepo's (2017) production function. It consists of a fixed number of tasks that can notionally be performed by human labor alone. A share $\beta$ of these tasks can be automated, i.e. can also be produced by capital of type $K_{s}$ alone.

Following existing work on the micro-foundations of productive structures of automatable work (e.g. DeCanio 2016; Acemoglu and Restrepo 2017), we can think about $T$ such tasks, so that $\beta T$ $(0 \leq \beta \leq 1)$ of these can be performed both by humans and robots, i.e. are automatable. The ease of substitution between the $(1-\beta) T$ human-critical tasks (non-automatable) and the $\beta T$ potentially automatable tasks is determined by the parameter $\rho$, which implies the elasticity of substitution to be $\sigma_{\rho} \equiv 1 /(1-\rho)$. Strong complementarity (low $\rho$ ) means that the $T$ tasks are equally needed to produce output. In this case, even when all of the $\beta T$ tasks are actually automated (which will happen if the cost of production with robots are lower than production with humans), the economy will have robotized only $\beta T$ of all tasks and $(1-\beta) T$ tasks remain produced by human labor, which is the limit to robotization. On the other hand, a high value of $\rho$ means that the production process is able to intensify the provision of the $\beta T$ subset of tasks while relying less on the subset $(1-\beta) T$, without loss of output. In this case, the economy may be fully robotized (i.e. no human labor used in production) despite $\beta<1$, by only performing the $\beta T$ tasks that are automatable. In our actual equations, we will normalize $T$ to one, and assume that each task is performed by using either 1 unit of capital $K_{s}$ or one unit of labor.

The ability of the economy to specialize in a subset of all tasks (i.e. $\rho$ ) is clearly determined by factors such as demand (i.e. the relative economic value of the respective tasks) and openness to international trade. If some tasks are relatively more valuable than others, the economy can choose to increase its productivity by producing more of the relatively more valuable ones while decreasing (or terminating) the production of the less valuable tasks and perhaps importing them. In our model, we will abstract from these demand issues, and also from international trade. Instead, we will model the substitution between human labor and robot capital $K_{s}$ only in terms of the production function.

So far, we discussed the role of the parameters $\beta$ and $\rho$ in determining the possibilities of substitution between labor $L$ and robot capital $K_{s}$. $\beta$ indicates the degree of potential automation, while $\rho$ measures the ease of substitution between automatable and non-automatable tasks. The third and final parameter that plays a role in robotization is $b_{s}$, which measures the productivity of $K_{s}$. Similarly, $b_{L}$ measures the productivity of human labor. These parameters will determine whether or not a 
potentially automatable task will actually be automated. A higher (lower) $b_{s} / b_{L}$ ratio will provide incentives for a relatively robot (human) intensive production.

Similar to the way we define services to be provided by humans and robots as tasks, we define total economic output as a collection of productive activities. The outer level of the production function, with relevant parameters $a$ and $\mu$, defines how the two broad types of activities (i.e. human-like services, and pure capital services) can be combined to produce output. The parameter $a$ indicates the share of activities that are intensive in pure-capital services while $1-a$ is the share of activities that are intensive in human-like services.

The key parameter in the outer part of the production function is $\mu$, which determines the degree of substitution or complementarity between the activities intensive in the composite $K_{s}-L$ factor on the one hand, and $K_{o}$ on the other hand. The parameter $\mu$ can be seen as specifying the limitations of a process of structural change from productive activities that are intensive in $K_{o}$ (such as metal making, which requires blast furnaces), to a service-intensive economy that relies much more on activities that are intensive in the composite $K_{s}-L$ factor. The elasticity of substitution in this outer part is defined as $\sigma_{\mu} \equiv 1 /(1-\mu)$.

Our analysis of the economic effects of robotization relies on the assumption that $0<\rho \leq 1$ or $\sigma_{\rho}>1$, which emphasizes a state where automatable tasks are fairly well able to substitute non-automatable tasks, and vice versa. ${ }^{3}$ If $\rho<0$, robotization becomes much less of an issue. We will also assume $\rho>\mu$, and hence $\mu<0$ and $\sigma_{\mu}<1$. This means that labor $L$ can be substituted more easily with $K_{s}$ than the composite $K_{s}-L$ factor can be substituted with $K_{o}$. This assumption essentially follows from the particular way in which we break down aggregate capital into two categories (i.e. $K_{o}$ as inherently complementary to labor, and $K_{s}$ as inherently substitutable). The parameter $b_{o}$ (i.e. the productivity of $K_{o}$ ) plays a similar role to $b_{s}$ and $b_{L}$, i.e. it determines the cost-effectiveness of $K_{o}$ relative to the composite $K_{s}-L$ factor, and hence has an impact on the relative use of these two factors.

We do not analyse the parameters $b_{o}, b_{s}, b_{L} a, \beta, \mu$ and $\rho$ as a function of time. This implies that the state of technology is given. Robot technology is embodied in capital $K_{s}$, which can substitute for labor. $b_{s}$ and $\beta$ are a reflection of how far robot-technology has progressed (productivity-wise and substitutability-wise respectively), while $\rho$ is a reflection of the ability of the production process to (relatively) specialize in robotized subset of tasks. The analysis will be aimed at finding out how these parameters influence growth, and what this implies for the resulting distribution of income between capital and labor.

This production function may be used to represent a wide range of secular phenomena that may be observed over (recent) economic history. For example, we may interpret the rise of the services sector as a decrease of $a$ (which implies an intensification of activities that need human-like tasks), combined with an increase in $b_{L}$ (the modernization of the services sector leading to higher productivity of not yet robot-substitutable human labor). Frey and Osborne's increased automation risk means that more and more tasks (also in the services sector) are becoming automatable ( $\beta$ increasing), and also that 'robots' are becoming cheaper (higher $b_{s}$ ).

While the latter (increasing $\beta$ and $b_{s}$ ) may lead to worries of job loss and a decline of labor income, a continuing decrease of a may offset this tendency. However, the process of decreasing $a$ ('servicification' of the economy) may well have come close to an end. If this is the case, the 'new mode' of technological progress (increasing $\beta$ and $b_{s}$ ) may well have entirely different consequences for employment and wages than an 'old mode' of technological progress, which may be represented by increasing $b_{o}$ and $b_{L}$ without a corresponding increase in $\beta$ and $b_{s}$. In other words, the way in which our production function embodies different forms of technological change suggests that 'this time it may be different' in terms of the consequences of technological progress for labor markets. This is what we will investigate in the model that will now be presented.

There doesn't seem to be an emerging sector in the horizon that can achieve what services sector achieved in the past (1-a cannot increase). This might mean that this time it is different. 


\section{A simple growth model}

With the assumed values of the substitution parameters $\mu<0<\rho \leq 1$, (and associated $\left.\sigma_{\mu} \leq 1<\sigma_{\rho}\right)$, two special and extreme cases are of interest. One is where $\mu$ approaches $-\infty$. This is the case where capital $K_{o}$ and the composite factor $K_{s}-L$ are completely complementary $\left(\sigma_{\mu}=\right.$ 0 ), so that the outer form of the production function turns into the familiar Leontief form, as in

$$
Q=\min \left[b_{s} K_{s},\left[\beta\left(b_{s} K_{s}\right)^{\rho}+(1-\beta)\left(b_{L} L\right)^{\rho}\right]^{1 / \rho}\right]
$$

where the a parameter disappears.

The other case is when $\mu$ approaches zero, and the elasticity of substitution $\sigma_{\mu}$ converges to 1 . In this case, the outer part of the production function (1a) becomes the familiar Cobb-Douglas form, as in

$$
Q=A\left(b_{o} K_{o}\right)^{\alpha}\left(\left[\beta\left(b_{s} K_{s}\right)^{\rho}+(1-\beta)\left(b_{L} L\right)^{\rho}\right]^{1 / \rho}\right)^{1-\alpha}
$$

where $A$ is an arbitrary new parameter that we set to 1 without loss of generality.

We use the production function (1a), and in particular (1b) and (1c), in a simple Solow-like growth model (Solow 1956) with exogenous savings, and without technological progress and without population growth. A first assumption in this model is that labor supply is completely inelastic:

$$
L=N
$$

In this equation $N$ is the labor force, which is exogenous.

In order to be able to analyse the functional income distribution, we distinguish between income from capital, and income from labor. The latter is earned solely by the members of the labor force $N$, while income from capital is earned by capital-owners. For most of the analysis, we will assume that capital owners and workers are separate groups, i.e. nobody is both a capital owner and a worker. Only at the last stage of the analysis will we relax that assumption.

Related to this, we also implement separate savings rates for labor income and capital income. This requires us to first define these two types of income. We obtain the (real) factor prices of the three production factors by their marginal products, and use these to obtain shares of the factor in total income (denoted by $\varpi$ with appropriate subscripts), which for the general form of the production function (1a) looks as follows:

$$
\begin{gathered}
\varpi_{L} \equiv \frac{p_{L} L}{Q}=\frac{\partial Q}{\partial L} \frac{L}{Q}=(1-\alpha)(1-\beta) \frac{\left(b_{L} L\right)^{\rho} \Theta_{L S}^{\mu / \rho}}{\Theta_{L S} \Theta_{T}} \\
\varpi_{S} \equiv \frac{p_{s} K_{s}}{Q}=\frac{\partial Q}{\partial K_{s}} \frac{K_{s}}{Q}=(1-\alpha) \beta \frac{\left(b_{s} K_{s}\right)^{\rho} \Theta_{L S}^{\mu / \rho}}{\Theta_{L S} \Theta_{T}} \\
\varpi_{o} \equiv \frac{p_{o} K_{o}}{Q}=\frac{\partial Q}{\partial K_{o}} \frac{K_{o}}{Q}=\alpha \frac{\left(b_{o} K_{o}\right)^{\mu}}{\Theta_{T}}
\end{gathered}
$$

In these equations, we define $\Theta_{T} \equiv \alpha\left(b_{o} K_{o}\right)^{\mu}+(1-\alpha)\left[\beta\left(b_{s} K_{s}\right)^{\rho}+(1-\beta)\left(b_{L} L\right)^{\rho}\right]^{\mu / \rho}$ and $\Theta_{L S} \equiv \beta\left(b_{s} K_{S}\right)^{\rho}+(1-\beta)\left(b_{L} L\right)^{\rho}$, while $p_{L}, p_{c}$ and $p_{s}$ are the prices of labor, $K_{s}$ and $K_{o}$, respectively. When the outer-part of the production function is Cobb-Douglas (equation 1c), this yields a share $a$ for capital $K_{o}$, and a share $1-a$ for the composite $K_{s}-L$ factor (sum of $3 a$ and $3 b$ ). We also define the shares of $L$ and $K_{s}$ in joint income of the composite factor, as $\nu_{L} \equiv \varpi_{L} /\left(\varpi_{L}+\varpi_{s}\right)$ and $\nu_{s} \equiv \varpi_{s} /\left(\varpi_{L}+\varpi_{s}\right)$.

Next, we assume that savings out of labor income are zero, while a fraction $s_{K}$ of capital income (both robot capital and complementary capital) is saved. This makes total savings $(S)$ equal to

$$
S=s_{K} Q\left(\varpi_{o}+\varpi_{s}\right)
$$


All savings are invested. The investment process is described by the following two equations:

$$
\begin{gathered}
S=I=I_{o}+I_{s} \\
\dot{K}_{o}=I_{o}-\delta K_{o}, \dot{K}_{s}=I_{s}-\delta K_{s}
\end{gathered}
$$

Equation (5) specifies that all savings are used for investment $(I)$ in capital. Equation (6) specifies the motion of both capital stocks, where we use a dot above the capital stock variables to denote their change over time (time derivative). Capital stocks decline by a fixed depreciation rate $\delta$ (which for simplicity we set equal between the two capital types) and increase by investment. In order to determine how investment is distributed over the two types of capital, we assume profit maximization leading to the marginal products of the two types of capital being equal to each other. The (formal) implications of this assumption will be investigated below.

Finally, we add a last equation that defines consumption by a national income identity:

$$
C=Q-S
$$

We now proceed to analyse the model in terms of its implications for growth and distribution.

\section{Perpetual growth}

The basic insight about growth in our model is similar to that of the original Solow-model without technological change (Solow 1956): growth of output per worker can increase as long as the amount of capital per worker keeps growing. Without population growth (as we assume), this is the case as long as net investment $(I-\delta K)$ is positive.

To derive the conditions under which this will happen, we start by factoring out $K_{s}$ from the inner part of the production function (1a), which gives rise to

$$
Q=\left(\alpha\left(b_{o} K_{o}\right)^{\mu}+(1-\alpha)\left(K_{s}\right)^{\mu}\left[\beta b_{s}^{\rho}+(1-\beta) b_{L}^{\rho}\left(\frac{L}{K_{s}}\right)^{\rho}\right]^{\mu / \rho}\right)^{1 / \mu}
$$

If the capital stock $K_{s}$ keeps growing, and with constant $N=L$, the term $L / K_{s}$ goes to zero, and hence equation (8) will converge to

$$
Q=\left(\alpha\left(b_{o} K_{o}\right)^{\mu}+(1-\alpha)\left(\beta^{1 / \rho} b_{s} K_{s}\right)^{\mu}\right)^{1 / \mu}
$$

We assume that the allocation of investment over the two types of capital is profit maximizing, which implies that the marginal products of the two capital stocks are equal $\left(d Q / d K_{s}=d Q / d K_{o}\right)$. These marginal products are obtained by differentiating the function (9) with respect to $K_{o}$ and $K_{s}$. Then, with some rearranging, the profit maximization condition yields

$$
K_{o}=K_{s}\left(\frac{\alpha b_{o}^{\mu}}{(1-\alpha) b_{s}^{\mu} \beta^{\mu / \rho}}\right)^{1 /(1-\mu)}
$$

We now focus on the special case where capital $K_{o}$ and the composite $K_{s}-L$ factor are pure complements. This implies that $\mu$ approaches $-\infty$, and that $\sigma_{\mu}=0$. We leave details of the alternative assumption $\sigma_{\mu}=1$ to the appendix. Under the assumption $\sigma_{\mu}=0$, equation (10a) will reduce to

$$
K_{o}=K_{s} \frac{\beta^{1 / \rho} b_{s}}{b_{o}}
$$

Now we substitute equation (10b) into the production function (9), which after some rearranging will yield a relation between output and only one type of capital:

$$
Q=b_{s} K_{s} \beta^{1 / \rho}
$$


Net investment $(I-\delta K)$ can be written as $s_{K} Q-\delta\left(K_{o}+K_{s}\right)$. Growth requires this to be positive, and using equations (10b) and (11), we arrive at the growth condition

$$
b_{s} \beta^{1 / \rho}>\frac{\delta b_{o}}{s_{K} b_{o}-\delta}=\frac{1}{\left(s_{K} / \delta\right)-\left(1 / b_{o}\right)}
$$

If this condition is satisfied, growth is perpetual, and it arises only from investment in $K_{s}$ (robots), without improvement in technology (robot or otherwise). ${ }^{4}$ Once a parameter state is reached in which robots are cost-effective enough ( $b_{s}$ high enough), are sufficiently able to substitute human labor ( $\beta$ and/or $\rho$ large enough), and the savings rate $s_{K}$ is high enough, growth will be self-propelling by investment in $K_{s}$ alone. A higher $b_{o}$ (i.e. higher productivity of the non-robot capital) also contributes positively to the likelihood of perpetual growth.

The appendix shows that if we use the production function (1c), i.e. when the elasticity of substitution $\sigma_{\mu}=1$ instead of 0 , the growth condition becomes

$$
b_{s} \beta^{1 / \rho}>\frac{1}{1-\alpha}\left(\frac{\delta}{s_{K}\left(\alpha b_{o}\right)^{\alpha}}\right)^{1 / 1-\alpha}
$$

The growth condition (12a) is more stringent than (12b), i.e. perpetual growth is harder to achieve when the outer part of the production function allows no substitution (i.e. lower opportunities for structural change). For example, when $s_{K}=\delta\left(b_{s}+b_{o}\right) /\left(b_{s} b_{o}\right)$ even $\beta=1$ will not allow perpetual growth in equation (12a) (net investment is zero in this case), while (12b) will still allow growth (this holds for a wide range of $b_{s}$ and $b_{o}$ values). However, numerical analysis suggests that these differences are not very large beyond the threshold $s_{K}=\delta\left(b_{s}+b_{o}\right) /\left(b_{s} b_{o}\right)$.

Figure 1 shows how the growth condition depends on $\rho, \beta$ and $b_{s}$. The lines labeled as 'CD' refer to the production function (1c), i.e. condition (12b) and $\sigma_{\mu}=1$, while the lines labeled as 'Leon' refer to $\sigma_{\mu}=0$ (condition 12a and production function $1 \mathrm{~b}$ ). $\delta$ has been set to 0.05 in this figure, and $a=0.3, b_{o}$ $=1$ and $s_{K}=0.4$. Separate curves for different values of $b_{s}$ have been drawn. When $\rho=0, \beta$ always needs to be 1 for the growth equation to be satisfied, irrespective of $b_{s}$ (and other parameters). For larger values of $\rho$, the threshold value of $\beta$ becomes lower, ceteris paribus (and vice versa). Increasing the value of $b_{s}$ (i.e. making robot capital more productive) will make the growth condition

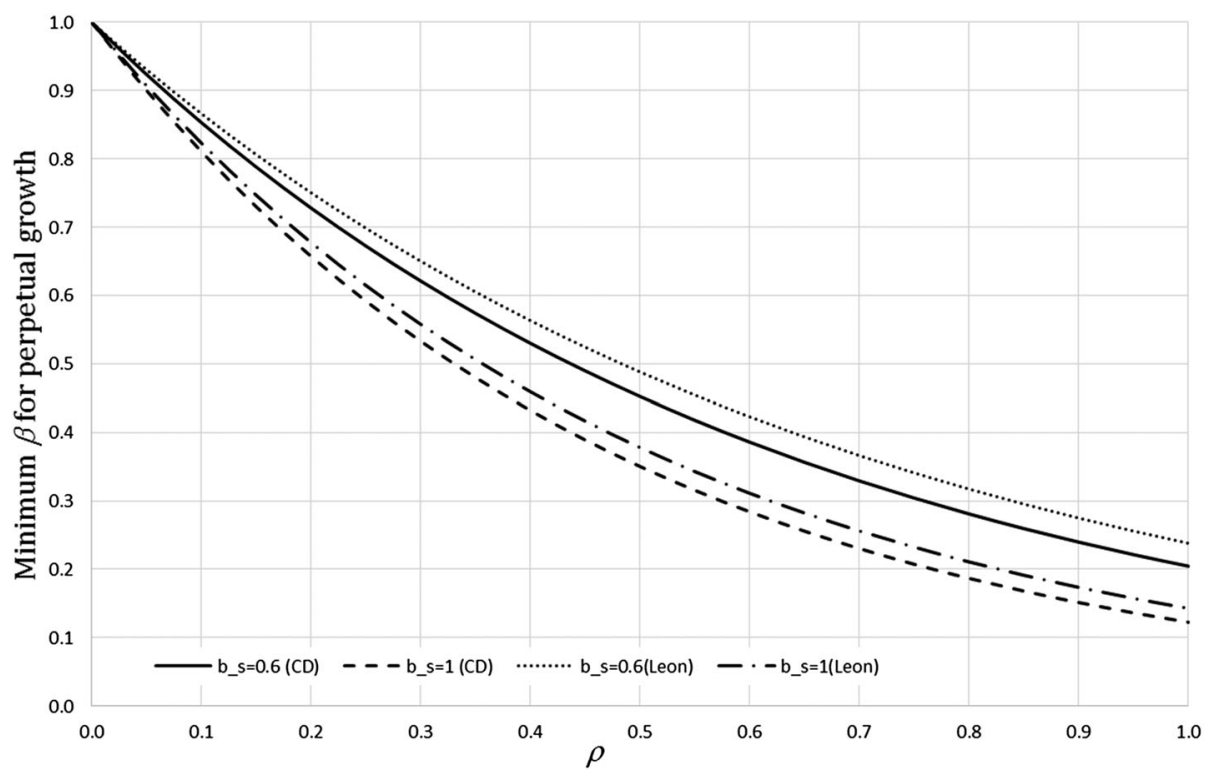

Figure 1. The growth condition in terms of $\beta$ and $\rho$. 
less stringent, for either form of the production function. The figure also confirms the earlier point that the Leontief outer-form yields a more stringent growth condition than the Cobb-Douglas form. Finally, note that Figure 1 clearly shows that we do not need $\rho=1$ (Prettner's strict assumption) to yield perpetual growth.

Equation (11) implies that the growth rate of output in the steady state, i.e. where $L / K_{s}$ goes to zero, and with $\sigma_{\mu}=0$, is equal to the growth rate of the capital stock $K_{s}$. Without population growth (as assumed), this growth rate, which will be denoted by $g_{Q}$, is also equal to the growth rate of per capita output. The growth rate of the capital stock - and hence output - is equal to net investment divided by $\left(K_{o}+K_{s}\right)$. To obtain this, we use equations (10b) and (11) to write:

$$
g_{Q}=\frac{I-\delta\left(K_{o}+K_{s}\right)}{K_{o}+K_{s}}=\frac{s_{K} Q}{K_{o}+K_{s}}-\delta=s_{K} \frac{b_{o} b_{s} \beta^{1 / \rho}}{b_{o}+b_{s} \beta^{1 / \rho}}-\delta
$$

In the appendix, we show that using similar logic, the growth rate in case of production function (1c) and $\sigma_{\mu}=1$ is equal to

$$
g_{Q}=s_{K}\left(\alpha b_{o}\right)^{\alpha}\left(b_{s}(1-\alpha) \beta^{1 / \rho}\right)^{1-\alpha}-\delta
$$

These expressions show that the steady-state growth rate depends positively on $b_{s}, \beta$ and $\rho$ (the 'robot parameters'), as well as on the savings rate. The depreciation rate has a negative impact on the growth rate, while the effect of $a$ (in case of $13 \mathrm{~b}$ ) on the growth rate is ambiguous.

Figure 2 illustrates the growth rate as a function of $\rho$. The figure uses $b_{o}=1, b_{s}=0.6, \beta=0.5, a=0.3$, $\delta=0.05$ and $s_{K}=0.4$. The solid line represents the growth rate when $\sigma_{\mu}=0$ (equation 13a), the dotted line is for $\sigma_{\mu}=1$ (equation 13b). Growth takes off after the threshold values for $\rho$ consistent with growth conditions (12a) and (12b). Higher substitutability between $K_{o}$ and the composite $K_{s}-L$ factor influences the growth rate positively, as the dotted line is always above the solid line. Plotting the growth rate with alternative parameter values suggests that this is a fairly general result, although the growth rates converge for high values of $b_{s}$ and $\beta$.

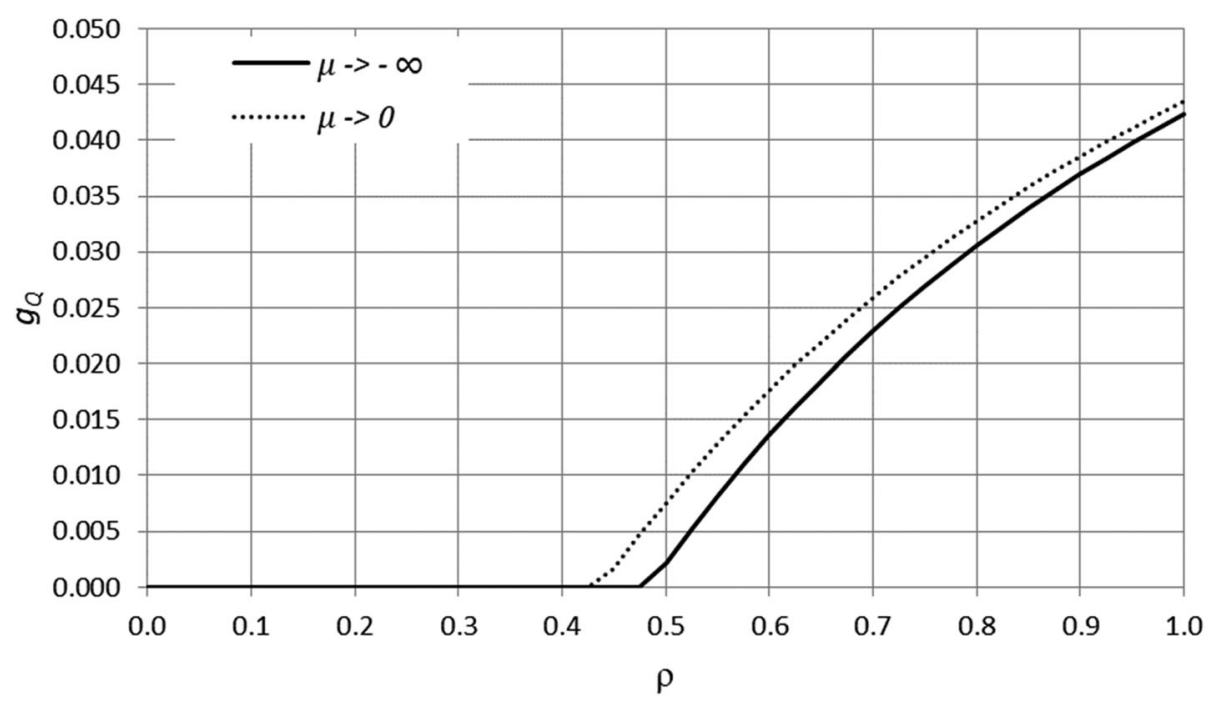

Figure 2. The perpetual growth rate. 


\section{Perpetual growth and labor income}

How does labor income evolve in a perpetually growing economy, both in terms of its share of total income, and in terms of the wage rate? The key element of perpetual growth is capital accumulation, both in terms of $K_{o}$ and $K_{s}$. Our question is therefore how the wage rate and the share of wages in total income are affected by the growth rates of both capital stocks. As DeCanio (2016) shows, the answer to this question strongly depends on the kind of production function that is applied, and in particular on the second derivative of output with respect to the production factors. If the production function contains just two production factors, the price paid for one production factor will never be influenced negatively by the other factor. In other words, if homogenous labor is combined with just one kind of capital, the questions we are asking here would be of little relevance.

However, in the kind of nested production function with three production factors that we use, dynamics of factor payments are more complicated. These production functions support the idea (which, as DeCanio (2016) briefly summarizes, has been around at least since the days of Marx and Ricardo) that technological change by accumulation of capital may affect labor income in a negative way. To investigate this, we derive the (partial) elasticities of the labor income share and of the wage rate, with respect to growth of the capital stock. We will denote these elasticities by $\varepsilon$ (appropriately subscripted), and start with the elasticity of the labor income share with respect to the capital stock $K_{o}$, which we derive for the general form of the production function (1a):

$$
\varepsilon_{o} \equiv \frac{\partial \varpi_{L}}{\partial K_{o}} \frac{K_{o}}{\varpi_{L}}=-\mu \frac{\left(b_{o} K_{o}\right)^{\mu}}{\Theta_{T}}=-\mu \varpi_{o}
$$

Because $\mu<0$ and $\varpi_{o}>0$, this is strictly positive, which implies that the partial effect of accumulation of the capital stock $K_{o}$ on the share of labor income is positive. In this sense, capital $K_{o}$ is truly labor augmenting.

Similarly, we derive the elasticity of the labor income share with respect to the capital stock $K_{s}$ as (remember that $\nu_{s}=\left(\beta\left(b_{s} K_{s}\right)^{\rho}\right) / \Theta_{L S}$ is the share of $K_{s}$ in joint income of the composite $K_{s}$ and $L$ factor)

$$
\varepsilon_{s} \equiv \frac{\partial \varpi_{L}}{\partial K_{s}} \frac{K_{S}}{\varpi_{L}}=\frac{\beta\left(b_{S} K_{S}\right)^{\rho}}{\Theta_{L S}}\left[\mu\left(1-\frac{(1-\alpha) \Theta_{L S}^{\mu / \rho}}{\Theta_{T}}\right)-\rho\right]=v_{s}\left(\varpi_{o} \mu-\rho\right)
$$

With $\mu<0, \rho>0$ and both income shares positive, this expression is strictly negative, i.e. the accumulation of the robot capital stock $K_{s}$ will have a negative partial effect on the share of labor income. Thus, we see an interesting contradiction: capital accumulation of type $K_{o}$ augments labor income, while accumulation of $K_{s}$ affects it negatively. This strong conclusion is a result of the labor-substituting nature of robot capital, and the labor-augmenting (complementary) nature of other capital.

Which of these two effects will dominate depends on the growth rates of both capital stocks, and the income shares and parameters in equations (14) and (15). In particular stages of the transient towards the steady state growth path, either one effect may dominate, and as a result the labor income share may either increase or decrease. For example, if the rate of accumulation of $K_{o}$ is high (low) as compared to that of $K_{s}$, we may expect that the share of labor income will rise (fall). However, in the steady state, the growth rates of both types of capital are equal to each other (by equation 10), and hence we may add up equations (14) and (15) to yield the elasticity of the labor income share with respect to total capital accumulation:

$$
\varepsilon_{o s} \equiv \varepsilon_{o}+\varepsilon_{s}=-\mu \varpi_{o}+v_{s}\left(\varpi_{o} \mu-\rho\right)=-\mu \varpi_{o}\left(1-v_{s}\right)-v_{s} \rho
$$

For $v_{s}<1$ and $\mu<0$, this may either be positive or negative, while for $\mu=0$ (which is the special case of production function $1 \mathrm{c}$ ), or $v_{s}=1$, the expression will become strictly negative. To see that 
the latter $\left(v_{s}=1\right)$ is indeed the case along the steady state growth path, we rewrite equation (3a) as

$$
\varpi_{L}=(1-\alpha)(1-\beta) \frac{\left(L / K_{s}\right)^{\rho} b_{L}^{\rho} K_{s}^{\mu}\left(\beta b_{s}^{\rho}+(1-\beta) b_{L}^{\rho}\left(L / K_{s}\right)^{\rho}\right)^{(\mu-\rho) / \rho}}{\Theta_{T}}
$$

This shows that in the steady state, when $L / K_{s} \rightarrow 0, \varpi_{L}$ will also converge to zero. Consequently, $v_{s}$ will converge to one in the steady state, which implies that equation (16) will eventually become negative. Thus, the share of labor income will decline towards zero in the steady state. ${ }^{5}$

Does the same hold for the wage rate (which we will denote as $W=\partial Q / \partial L$ )? To answer this question, we derive similar elasticities as before, this time for the wage rate with respect to both capital stocks. We denote these elasticities by $\epsilon$, and find them to be equal to

$$
\begin{gathered}
\epsilon_{o} \equiv \frac{\partial W}{\partial K_{o}} \frac{K_{o}}{W}=(1-\mu) \frac{\left(b_{o} K_{o}\right)^{\mu}}{\Theta_{T}}=(1-\mu) \varpi_{o} \\
\epsilon_{S} \equiv \frac{\partial W}{\partial K_{s}} \frac{K_{s}}{W}=\frac{\beta\left(b_{s} K_{s}\right)^{\rho}}{\Theta_{L S}}\left[\frac{(1-\alpha) \Theta_{L S}^{\mu / \rho}}{\Theta_{T}}+\mu\left(1-\frac{(1-\alpha) \Theta_{L S}^{\mu / \rho}}{\Theta_{T}}\right)-\rho\right]=v_{s}\left(1-\rho-\varpi_{o}(1-\mu)\right) \\
\epsilon_{o s} \equiv \epsilon_{o}+\epsilon_{S}=v_{s}(1-\rho)+\varpi_{o}(1-\mu)\left(1-v_{s}\right)
\end{gathered}
$$

Equation (18) is strictly positive, i.e. the partial effect of capital accumulation of type $K_{o}$ on the wage rate is positive, either in the steady state or in a transient towards it. Hence the analysis for the wage rate confirms the conclusion of the labor-augmenting nature of Ko that we arrived at in the analysis for the labor income share (equation 14).

Equation (19) may either be positive or negative, depending on parameter values and income shares. For the special case $\mu=0$ (production function 1c), we have $\varpi_{0}=\alpha$, and the sign of equation (19) depends on the sign of $(1-\rho-a)$ : if $\rho>1-a$, the partial effect of capital accumulation of type $K_{s}$ on the wage rate will be negative, otherwise it will be positive.

Equation (20), which holds only in the steady state when the rates of accumulation of both types of capital are equal, is strictly positive (it can be shown that the threshold value for $\rho$ to make this equation negative lies above 1 , which is ruled out). Hence in the steady state, the wage rate will rise, although the share of wages in income will decline. The conclusion is that perpetual growth by robots makes labor better off in absolute terms (the wage rate), but in relative terms (income distribution between capital and labor), workers clearly are victims of robots.

\section{Distributional policies}

The remainder of the paper will be devoted to a discussion of two possible ways of fighting inequality that results from growth by robots. The first is a social protection policy that taxes income from capital ownership and re-distributes the revenue of this tax to wage earners. We implement this by a fixed tax rate $\tau$ raised every period. The second option introduces savings out of wage income, thus enabling wage earners to invest in capital (of both types) and complement their wages by capital income.

In order to undertake this analysis, we numerically simulate the model rather than provide analytical solutions. We use production function (1c) in these simulations, i.e. the elasticity of substitution $\sigma_{\mu}$ $=1$. We use discrete time, i.e. for every period in the simulation, we (i) calculate output using the existing capital stocks and available labor, (ii) calculate the income shares and associated savings, (iii) numerically solve the investment allocation problem and assign total savings to the two different kinds of investment, (iv) update the capital stocks, and return to step (i) for a new period. We set initial values of $K_{o}$ and $K_{s}$ to 100 and 0.1 respectively, and $N=100$ throughout all simulations. Parameter values are $a=0.3, \delta=0.05, s_{K}=0.4, b_{o}=b_{s}=b_{L}=1, \beta=0.4, \rho=0.7$. These parameter values ensure perpetual growth (without taxes). We simulate 400 periods and assure that convergence in the growth rates is achieved at that point. 
We start the discussion with the tax option, which can be seen as the implementation of a universal basic income (Van Parijs and Vanderborght 2017). ${ }^{6}$ The obvious drawback of this is that taxes will hurt capital accumulation by reducing the funds available for investment, and thereby lowers the perpetual growth rate. Figure 3 shows the result. Without any taxes and re-distribution, we observe a growth rate of about $3.7 \%$, and a share of labor income in total income that is very close to zero. When the tax rate rises, the growth rate declines, until it becomes very close to zero at $\tau=0.5$.

The impact of the re-distributed tax on the share of income is about equal to the tax rate $\tau$ itself, because it is in effect almost a tax on total income (wage income is very small when substantial growth occurs). Thus, in order to reach a labor income share of about $0.4-0.6$, we need a tax rate of about $40 \%$. But this essentially makes growth go away.

Note that our simulation of universal basic income, as our entire analysis, assumes that the savings rate is exogenous and fixed. This may not be a very appropriate assumption in this context, as the tax may have an impact on the savings rate. This is explored in the literature on optimal taxation (Stern 1987), in which the Atkinson and Stiglitz (1976) theorem is a major result. In this light, a capital income tax (as we are assuming in the simulation) is usually considered as distortive, with a negative impact on capital accumulation/savings (Judd 1985; Chamley 1986). This suggests that the effect of the tax in our simulation would be to lower the savings rate, thus exacerbating the impossibility of a universal basic income funded by a capital income tax with perpetual growth.

Next, we look at a case where workers save and invest in capital, following Freeman's (2014) idea that workers 'can rule the world' by owning robots. To this end, we modify equation (4) as follows (note that we also substitute income shares that apply to the case of production function 1c):

$$
S=s_{K} Q\left[\alpha+(1-\alpha) \frac{b_{s} K_{s}^{\rho}}{b_{s} K_{s}^{\rho}+b_{L} L^{\rho}}\right]+s_{L}(1-\alpha) Q \frac{b_{L} L^{\rho}}{b_{s} K_{s}^{\rho}+b_{L} L^{\rho}}
$$

where $s_{L}$ is a new parameter that represents the savings rate out of labor income. Note that for $s_{L}=0$ and production function (1c), equation (21) reduces to equation (4), i.e. the model is as before. Note also that equation (21) assumes that savings rates are specific to income category, i.e. when a worker has both labor income and capital income, that worker applies two distinct savings rates $\left(s_{L}\right.$ and $\left.s_{K}\right)$. All savings are invested. We keep track of which part of the two capital stocks is owned by workers, and which part by capital owners. The ownership of capital does not impact the growth rate in any way, but $s_{L}>0$ does imply that the total amount of savings is larger, and hence the growth rate is also

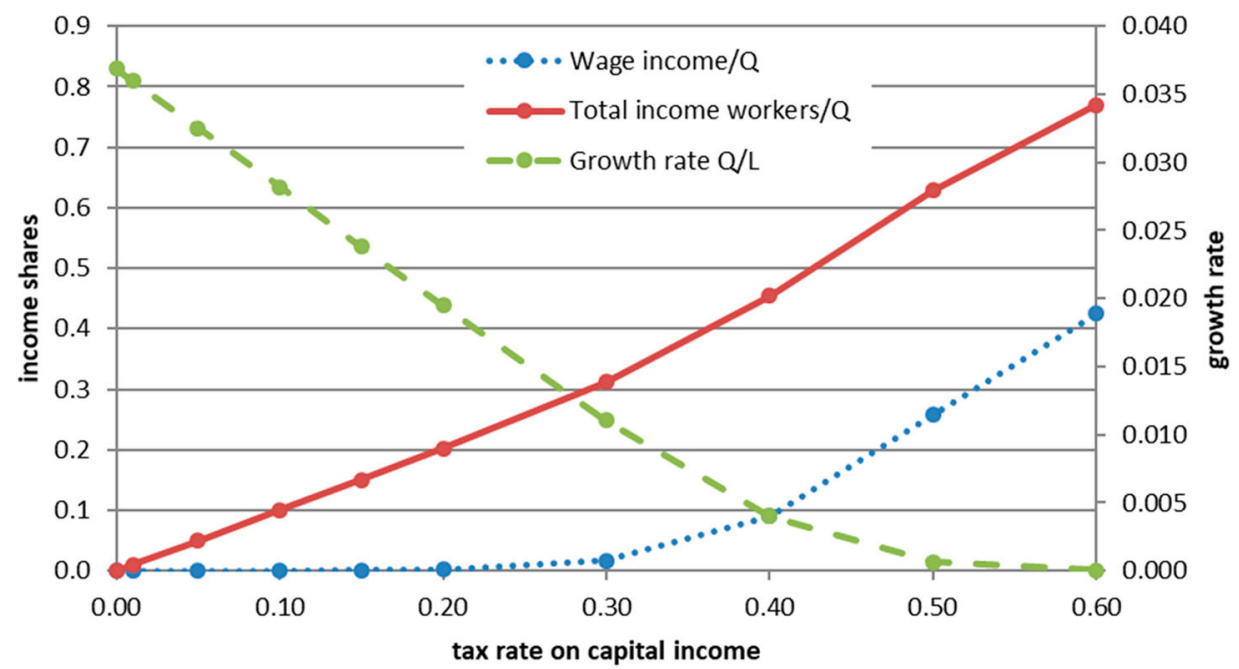

Figure 3. The effects of income re-distribution based on a capital income tax. 
larger. But this is a small effect, because savings out of wages is a small amount, because wages as a share of income (the source of extra savings) are near zero when growth is substantial.

Figure 4 presents the results of the experiment, using values for $s_{L}$ from 0 to 0.6 . We set $\rho=0.5$ for this analysis, and all other parameters as before. Growth increases with the savings rate, but this effect is very small as indicated by the scale of the vertical axis on the right, which covers a difference of only 0.00025 . The effects on distribution are much more substantial. Where workers' income consists of wages only, without saving, it is near to zero as a share of total income, as expected. With positive savings out of labor income, this increases rapidly for small savings rates $s_{L}$, to about $65 \%$ when $s_{L}$ $=0.1$, and well above $95 \%$ for $s_{L}=0.6$. Wages as a share of total workers' income decline rapidly for positive values of $s_{L}$, and are negligible already for $s_{L}=0.1$.

Thus, we see that assuming positive workers' savings does not affect our conclusions about the decline of wages as a share of GDP with perpetual growth. If workers save, they raise the growth rate because more capital is accumulated, but the conclusions of the model remain intact otherwise. Savings by workers do affect their income substantially, but this is because they become capital income earners in addition to being workers.

Concluding from the two experiments aimed at realizing a reduction inequality, it seems that taxing and re-distributing is much less effective than workers' savings and investment. Perpetual growth by robots causes inequality between workers and capital owners, and the key to reducing this inequality lays in transforming workers to capital owners. In this model, robots practically make human labor go away, but provide a source of riches for their owners.

\section{Summary and conclusions}

Our analysis, in particular the production function that we use, starts from the assumption that technological progress in the form of machine learning and artificial intelligence is of a fundamentally new nature. This form of technological development produces a form of capital that substitutes for human labor rather than augmenting it. Our model is aimed at investigating the consequences of this feature for labor markets, in particular wages and the wage share of total income.

Our analysis illustrates that labor-substituting technological progress can generate perpetual growth, i.e. sustained growth of per capita output with a given state of technology. This suggests

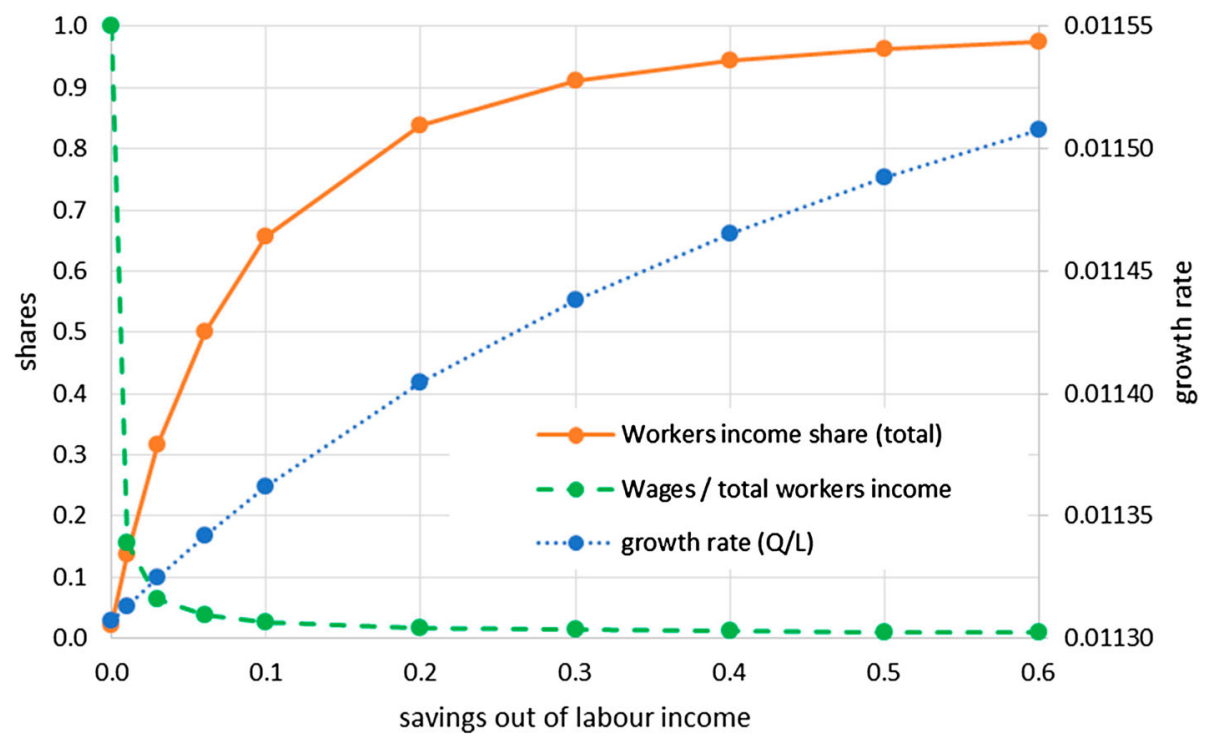

Figure 4. Distributional and growth effects of labor income saving. 
three main factors in determining whether the robot-technology will generate perpetual growth: the extent to which the technology can automate human labor tasks, how cheap the technology can be implemented, and how well automated tasks can substitute tasks performed by humans in the aggregate production process. Based on empirical work by, among others, Frey and Osborne (2017), Arntz, Gregory, and Zierahn (2016) and Nedelkoska and Quintini (2018), we argue that technologies such as machine learning, mobile robotics and artificial intelligence (in short, 'robots') are indeed making advances in these dimensions, and therefore may in the future be able to provide this kind of labor-substituting technology leading to perpetual growth.

Our model was able to derive conditions for perpetual growth to occur, and expressions for the perpetual growth rate. Perpetual growth is more likely to occur, and the growth rate will be higher, when robot technology is more advanced. In particular, we show that robot-technology does not have to offer complete or even near-complete substitutability for human labor in order to generate perpetual growth. In other words, even if artificial intelligence remains imperfect in the near future, perpetual growth may become a reality. Previous models of perpetual growth applied stricter assumptions about the level of advancement of the underlying technology.

In a future where robots generate perpetual growth, income from human labor will fetch a negligible part of total income in the economy, even though the absolute wage rate will rise as a result of robot-based perpetual growth. This means that perpetual growth makes workers better off in an absolute way, but worse off in a relative way. This implies that without social protection policy, income inequality may rise to unprecedented levels in a future economy. We implemented some simulation experiments in which two potential kinds of social protection are considered.

In one experiment, income from robots was taxed and transferred to those who are living only on a wage income. This can be seen as the implementation of a universal basic income, in a budget-neutral way. The drawback of the tax is that it reduces funds available for investment in capital, which is the source of perpetual growth. We assumed that the tax does not influence the savings rate (i.e. that it is paid proportionally out of consumption and investment). The main finding was that in order to reduce inequality in a substantial way, i.e. to keep the income share of wage owners (including the tax transfer or universal basic income) at a level comparable to a pre-perpetual growth state of the economy, growth will be reduced substantially. This suggests that it may be difficult to fight inequality by a universal basic income if growth becomes very much dependent on robot-technology.

The other policy option that was considered was workers' savings, i.e. saving out of labor income. In this way, workers become also capital owners (and we assume that their savings rate on capital income is equal to that of 'pure' capital income earners). This generates extra savings and investment rather than reduce it, and hence is growth-enhancing. The growth effect is small, however, because labor income remains small and hence does not generate much savings. However, 'workers' are able to accumulate a capital stock, which becomes the main source of their income. Even a relatively modest savings rate for labor income (e.g. 10\%) reduces inequality very significantly.

Although this savings experiment could be seen as a voluntary arrangement, not dependent on policy, it may also be implemented as a forced savings scheme, comparable to pension schemes in many (European) countries. As such, it can be seen as a form of social protection policy, and one that seems relatively effective (more so than the universal basic income). With this kind of policy, the view in Albus (1976) about a robot-society as a 'peoples' capitalism' may indeed become true.

There are several open resource avenues that must be followed for the theory in this paper to become better founded and better able to think about a future economy in which robot-technology becomes dominant. For example, our growth model is relatively crude. It reflects Solow's model from the 1950s, and ignores advances made in growth theory since then. It remains to be shown whether endogenization of important factors such as savings and investment in technology (which we ignored completely) change any of the major conclusions about perpetual growth or the income distribution.

Also, work remains to be done about social protection policy. Due to the crudeness of our model, we were not able to analyse detailed form of such policies, or look at the various ways in which these 
policies could be instituted. The analysis does suggest, however, some directions for research on this topic, such as the relationship between a universal basic income and aggregate savings and investment. Relatively little seems to be known about this relationship, but our results suggest that it may be crucial for how well such a scheme could work.

In summary, our analysis points to the possibility that robot-technology will be a truly revolutionizing force, and calls for more research on the implications and policy processes that will be necessary to make it a soft revolution.

\section{Notes}

1. The emphasis on the pure employment effects is especially strong in the popular debate following Frey and Osborne. For example, The Guardian headlined 'Robots are the ultimate job stealers. Blame them, not immigrants', (https://www.theguardian.com/commentisfree/2018/feb/14/resentment-robots-job-stealers-arlie-hochschild) while Mother Jones warned that 'You Will Lose Your Job to a Robot-and Sooner Than You Think' (https://www. motherjones.com/politics/2017/10/you-will-lose-your-job-to-a-robot-and-sooner-than-you-think/).

2. We use the terms 'robots' to colloquially refer to a set of technologies that Frey and Osborne (2017) describe as 'machine learning'. See the next section.

3. Aghion, Jones, and Jones (2017) provide a model of automation in which $\rho<0$, and in which the conclusion on the share of wages in GDP differs sharply from the one that we draw in Section 6. In their model, the share of automated labor tasks keeps growing for ever, but never becomes one. Because labor and capital are complementary, labor remains asymptotically necessary, and therefore imposes a burden on the economy that is similar to Baumol's cost disease. The share of wages therefore does not decline in the steady state.

4. A brief comment on the interpretation of our $K_{s}$ production factor and its relation to perpetual growth seems in order. So far, we interpreted $K_{s}$ as pure capital, in which a certain exogenous state of knowledge is embodied, but which, in a perpetual growth regime, only accumulates and does not change in nature. Alternatively, we can think of $K_{s}$ as a stock of disembodied knowledge, which firms combine with capital $K_{o}$ and labor. In such an interpretation, the growth regime described in this section would still require R\&D (which is the accumulation of Ks). Marchese and Privileggi (2019) show how the generation of this kind of disembodied knowledge is compatible with competitive markets, and how growth in such a context leads to a declining share of labor in total income, as it does in our model (this is explored in the next section).

5. Using a production function very similar to ours, DeCanio (2016) estimates the elasticity of substitution between robots and human labor at which the labor share begins to decline. His estimations point to a value of the substitution parameter ( $\rho$ in our case) between 0.4 and 0.5 .

6. Our simulation is crude in that it taxes all capital income at an equal rate. Guerreiro, Rebelo, and Teles (2019) discuss and analyze a number of more sophisticated options for using tax instruments to combat income inequality with rising automation.

\section{Acknowledgements}

We thank three anonymous reviewers, Luc Soete, Thomas Ziesemer, Adriaan van Zon, Pierre Mohnen and participants at the UN Expert Group Meeting on 'Accelerated Technological Change, Artificial Intelligence, Automation and their Implications for Sustainable Development Targets' (Mexico City, 26-27 April 2018) for comments on an earlier version. The views expressed and any remaining errors remain solely our own.

\section{Disclosure statement}

No potential conflict of interest was reported by the authors.

\section{ORCID}

Bart Verspagen (D) http://orcid.org/0000-0001-6975-8141

\section{References}

Acemoglu, D. 1998. "Why Do New Technologies Complement Skills? Directed Technical Change and Wage Inequality." Quarterly Journal of Economics 113: 1055-1089. 
Acemoglu, D. 2002. "Technical Change, Inequality and the Labour Market." Journal of Economic Literature 40: 7-72.

Acemoglu, D., and A. Autor. 2011. "Skills, Tasks and Technologies: Implications for Employment and Earnings." In Handbook of Labour Economics, Volume 4b, edited by O. Ashenfelter, and D. Card, 1043-1171. Amsterdam: Elsevier.

Acemoglu, D., and P. Restrepo. 2017. "The Race Between Machine and Man: Implications of Technology for Growth, Factor Shares and Employment." NBER Working Paper, 22252. Cambridge. MA: National Bureau of Economic Research.

Aghion, P., B. F. Jones, and C. I. Jones. 2017. "Artificial Intelligence and Economic Growth." NBER Working paper, 23928. Cambridge, MA: National Bureau of Economic Research.

Albus, J. S. 1976. Peoples' Capitalism: The Economics of the Robot Revolution. New York: New World Books.

Arntz, M., T. Gregory, and U. Zierahn. 2016. "The Risk of Automation for Jobs in OECD Countries: A Comparative Analysis." OECD Social, Employment and Migration Working Papers, 189. Paris: OECD Publishing.

Atkinson, A. B., and J. E. Stiglitz. 1976. "The Design of Tax Structure: Direct Versus Indirect Taxation." Journal of Public Economics 6: 55-75.

Autor, D. 2015. "Why Are There Still So Many Jobs? The History and Future of Workplace Automation" Journal of Economic Perspectives 29: 3-30.

Autor, D., and D. Dorn. 2013. "The Growth of Low-Skill Service Jobs and the Polarization of the U.S. Labor Market." American Economic Review 103: 1553-1597.

Autor, D., D. Dorn, L. F. Katz, C. Patterson, and J. Van Reenen. 2017. "Concentrating on the Fall of the Labor Share." American Economic Review 107: 180-185.

Autor, D., F. Levy, and R. J. Murnane. 2003. "The Skill Content of Recent Technological Change: an Empirical Exploration." Quarterly Journal of Economics 118: 1279-1333.

Autor, D., and A. Salomons. 2018. "Is Automation Labor-Displacing? Productivity Growth, Employment, and the Labor Share." NBER Working Paper, 24871. Cambridge, MA: National Bureau of Economic Research.

Berman, E., J. Bound, and S. Machin. 1998. "Implications of Skill-Biased Technological Change: International Evidence." Quarterly Journal of Economics 113: 1245-1279.

Bessen, J. 2016. "How Computer Automation Affects Occupations: Technology, Jobs, and Skills." Law \& Economics Working Paper, 15-49. Cambridge, MA: Boston University School of Law.

Card, D., and J. E. DiNardo. 2002. "Skill-Biased Technological Change and Rising Wage Inequality: Some Problems and Puzzles." Journal of Labour Economics 20 (4): 733-783.

Chamley, C. 1986. "Optimal Taxation of Capital Income in General Equilibrium with Infinite Lives." Econometrica 54: 607622.

DeCanio, S. J. 2016. "Robots and Humans - Complements or Substitutes?" Journal of Macroeconomics 49: $280-291$.

Freeman, R. B. 2014. "Who Owns the Robots Rules the World." IZA World of Labor 5.

Freeman, C., and L. Soete. 1994. Work for All or Mass Unemployment. London: Pinter.

Frey, C. B., and M. A. Osborne. 2017. "The Future of Employment: How Susceptible are Jobs to Computerisation?" Technological Forecasting and Social Change 114: 254-280.

Guerreiro, J., S. Rebelo, and P. Teles. 2019. "Should Robots be taxed?" NBER Working paper, 23806. Cambridge, MA: National Bureau of Economic Research.

IMF. 2017. World Economic Outlook. Washington: IMF.

Judd, K. L. 1985. "Redistributive Taxation in a Simple Perfect Foresight Model." Journal of Public Economics 28: 59-83.

Karabarbounis, L., and B. Neiman. 2014. "The Global Decline of the Labor Share." Quarterly Journal of Economics 129: 61103.

Katsoulacos, Y. 1986. The Employment Effect of Technical Change: A Theoretical Study of New Technology and the Labour Market. Brighton: Wheatsheaf.

Lucas, R. 1988. "On the Mechanics of Economic Development." Journal of Monetary Economics 22: 3-42.

Marchese, C., and F. Privileggi. 2019. "A Competitive Idea-Based Growth Model." Economics of Innovation and New Technologies, preprint.

Murphy, K., W. C. Riddell, and P. M. Romer. 1998. "Wages, Skills and Technology in the United States and Canada." NBER Working Paper, 6638. Cambridge, MA: National Bureau of Economic Research.

Nedelkoska, L., and G. Quintini. 2018. "Automation, Skills Use and Training." OECD Social, Employment and Migration Working Papers. Paris: OECD Publishing.

Nelson, R. R., and S. G. Winter. 1982. An Evolutionary Theory of Economic Change. Cambridge, MA: Harvard University Press. Peretto, P. F., and J. J. Seater. 2013. "Factor-Eliminating Technical Change." Journal of Monetary Economics 60: 459-473. Pratt, G. A. 2015. "Is a Cambrian Explosion Coming for Robotics?" Journal of Economic Perspectives 29: 51-60.

Prettner, K. 2019. "A Note on the Implications of Automation for Economic Growth and the Labor Share." Macroeconomic Dynamics 23 (3): 1294-1301.

Romer, P. 1990. "Endogenous Technological Change." Journal of Political Economy 98: S71-S102.

Silverberg, G., and B. Verspagen. 1994. "Collective Learning, Innovation and Growth in a Boundedly Rational, Evolutionary World." Journal of Evolutionary Economics 4: 207-226.

Solow, R. M. 1956. "A Contribution to the Theory of Economic Growth." The Quarterly Journal of Economics 70: 65-94.

Stern, N. H. 1987. "Optimal Taxation." In The New Palgrave: A Dictionary of Economics Volume 1, 865-867. London: Palgrave MacMillan. 
Van Parijs, P., and Y. Vanderborght. 2017. Basic Income. A Radical Proposal for a Free Society and a Sane Economy.

Cambridge, MA: Harvard University Press.

Vivarelli, M. 1995. The Economics of Technology and Employment: Theory and Empirical Evidence. Aldershot: Elgar.

\section{Appendix}

\section{Additional derivations}

We present here some additional derivations on the growth properties of the model when we use production function (1c), i.e. where the outer part of the production function is Cobb-Douglas. We start with the condition for perpetual growth, which, as in the main text, is based on net investment $(I-\delta K)$ being positive. As in the main text, we start by factoring out $K_{s}$ from the CES part of the production function (1c), yielding

$$
Q=A\left(b_{o} K_{o}\right)^{\alpha} K_{s}^{1-\alpha}\left(\left[\beta b_{s}^{\rho}+(1-\beta)\left(\frac{b_{L} L}{K_{s}}\right)^{\rho}\right]^{1 / \rho}\right)^{1-\alpha}
$$

With the term $L / K_{s}$ going to zero, equation (A1) will converge to

$$
Q=A\left(b_{o} K_{o}\right)^{\alpha} K_{s}^{1-\alpha}\left(\beta^{1 / \rho} b_{s}\right)^{1-\alpha}
$$

Profit maximizing investment implies $d Q / d K_{s}=d Q / d K_{o}$, which, based on the production function (1c) and keeping in mind $L / K_{s} \rightarrow 0$, yields

$$
K_{o}=K_{s} \frac{\alpha}{1-\alpha}
$$

Substituting (A3) in (A2), we obtain

$$
Q=K_{s}\left(\frac{\alpha}{1-\alpha} b_{o}\right)^{\alpha}\left(\beta^{1 / \rho} b_{s}\right)^{1-\alpha}
$$

Using equations (A3) and (A4), the growth condition becomes

$$
\beta>\left(\frac{\delta}{s_{K}} \frac{1}{\left(\alpha b_{o}\right)^{\alpha}} \frac{1}{\left(b_{s}(1-\alpha)\right)^{1-\alpha}}\right)^{\rho /(1-\alpha)}
$$

The growth rate of the capital stock $K_{s}$, which by equation (A4) is equal to the growth rate of output, is equal to net investment divided by the capital stock itself. Using also equation (A3), we obtain

$$
g_{Q}=\frac{l-\delta\left(K_{o}+K_{s}\right)}{K_{o}+K_{s}}=\frac{s_{K} Q}{K_{o}+K_{s}}-\delta=s_{K}\left(\alpha b_{o}\right)^{\alpha}\left(b_{s}(1-\alpha) \beta^{1 / \rho}\right)^{1-\alpha}-\delta
$$

